\title{
Tribological and Mechanical Properties of Epoxy Reinforced by Hybrid Nanoparticles
}

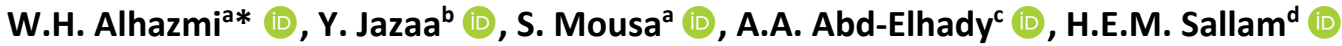 \\ a Faculty of Engineering, Jazan University, Jazan 706, Kingdom of Saudi Arabia.E-mail: waalhazmi@jazanu.edu.sa, samousa@jazanu.edu.sa \\ ${ }^{b}$ Faculty of Engineering, King Khalid University, Kingdom of Saudi Arabia. E-mail: yjazaa@kku.edu.sa \\ c Mechanical Design Dept., Faculty of Engineering, Helwan University, Cairo 11718, Egypt. E-mail: amrabdelfattah@m-eng.helwan.edu.eg \\ ${ }^{d}$ Faculty of Engineering, Zagazig University, Zagazig, Egypt. E-mail: hem_sallam@zu.edu.eg \\ * Corresponding author
}

https://doi.org/10.1590/1679-78256384

\begin{abstract}
In the present work, the nano-Aluminum oxide $\left(\mathrm{Al}_{2} \mathrm{O}_{3}\right)$, nano-Silicon Carbide (SiC), or a hybrid of them were infused into epoxy resin with an ultrasonic system with various weight percentage ratios of the nanoparticles. Small punch testing (SPT) and indirect tension testing were adopted to measure the tensile properties of the present nanocomposites. Pin-on-ring wear testing was also performed to examine wear performance of epoxy $\mathrm{Al}_{2} \mathrm{O}_{3}$ and $\mathrm{SiC}$ nanocomposites. The Finite Element Analysis method is introduced to simulate the indirect tension test and SPT to give a complete vision of the stress distribution in the nanocomposite specimen during the loading, and to examine its mode of failure. Good agreement between the numerical and experimental results was observed. The addition of nanoparticles from $\mathrm{Al}_{2} \mathrm{O}_{3}$ or $\mathrm{SiC}$ improves the wear resistance of epoxy. Furthermore, epoxy with nano- $\mathrm{Al}_{2} \mathrm{O}_{3}$ has a higher wear resistance than that with nano$\mathrm{SiC}$. The tensile strength and modulus of elasticity of epoxy are reduced by adding the $\mathrm{Al}_{2} \mathrm{O}_{3}$ nanoparticle. The synergistic effect is not observed in the present study.
\end{abstract}

\section{Keywords}

Nano-composites; mechanical properties; small punch test; tribological properties; 3D-FEA

\section{Graphical Abstract}

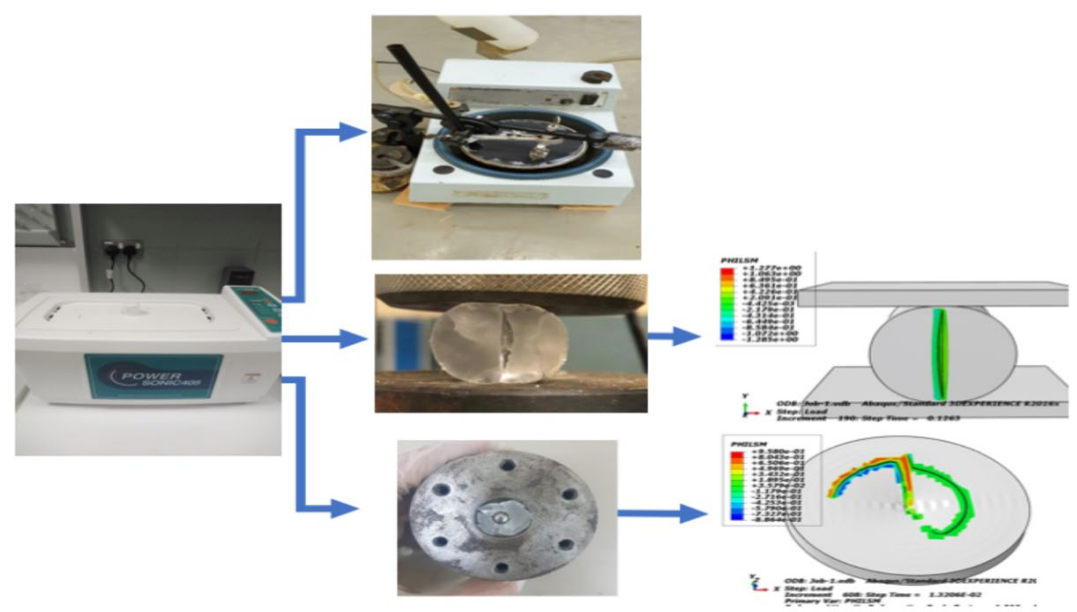




\section{INTRODUCTION}

Epoxy resins containing more than one compound belonging to the category of thermosetting resins have multiple specifications including adhesion strength, chemical stability, and electrical insulation (Ma et al.,2018, 2019;Zhang et al., 2018a; Hu et al.,2 018; Gu et al., 2019; Gong et al., 2019; He et al., 2019; Zhang et al. 2019). Because of these characteristics, these resins have been used widely as matrices in numerous applications (Zhang et al.,2018b). The addition of nanoparticles such as nano-ceramic, nano-wires, carbon nanotubes, and graphene structures to epoxy resins leads to an increase in desired mechanical properties (Kurahatti et al., 2014; Megahed et al., 2018, 2019, 2021; Agwa et al., 2020; Youssef et al., 2020). Because of crack pinning and plastic void growth, which arise from reinforcing the epoxy with nano-ceramics, the addition of nanoparticles contributes to increasing composite toughness (Jiang et al.,2014). As researchers have noted, a nanoparticle size that has a higher ratio of surface area to volume than that of larger-sized particles makes nano-size distinctions in the physical network structure. These characteristics are reflected as advantages in increased resistance of the composite, including nanoparticles for wearing rate, compared to larger particles; this type of nanoparticle can yield a layer of strong film that blends with wear debris (Ash et al., 2002; Schwartz and Bahadur, 2000).

A significant amount of research has confirmed the importance of the size and surface area of all nano- and microfillers to enhance the properties of the epoxy composites (Baller et al., 2011; Suzuki et al., 2011a). There is an increase in the strength of the composite when nano particles of aluminum oxide, $\mathrm{Al}_{2} \mathrm{O}_{3}$, are added to it. Furthermore, the effect of reactive $\mathrm{SiC}$ nanoparticles addition on sliding wear behavior of epoxy composites using a pin-on-ring configuration was studied by Luo et al. (2007). The result of adding SiC nanoparticles is an enhancement to the tribological performance of epoxy, namely, improving its wear properties. Dass et al. (2017) investigated the effect of adding nanoparticles of $\left(\mathrm{SiC}, \mathrm{Al}_{2} \mathrm{O}_{3}\right.$, and $\left.\mathrm{ZnO}\right)$ on the mechanical and tribological properties of epoxy composites. They concluded that the lowest specific wear rate was found with $\mathrm{Al}_{2} \mathrm{O}_{3}$ nanocomposite. Furthermore, they noted that better mechanical and wear properties for the different composite materials were obtained with two weight\% filler content.

Various evaluation techniques were used to evaluate the tensile properties, flexural properties, and tribological properties for such composites using conventional techniques (Rong et al., 2001). Nowadays, the Small Punch Test (SPT) is used to evaluate the mechanical properties for various kinds of composites, especially metal matrix composites and polymer matrix composites (Moreno, 2016). The SPT is a technique used to evaluate the mechanical behavior of miniaturized thin disks. The use of SPT has emerged as a potentially useful technique for mechanical characterization using small specimens (Xu and Van Hoa, 2008).Therefore, one of the main objectives of the present work is to ensure the accuracy of the results obtained from SPT by comparing them with the results obtained from Diametral Tensile Testing (DTT).

The main objective of the present work is improving the mechanical and tribological properties of commercial epoxy by adding aluminum oxide $\left(\mathrm{Al}_{2} \mathrm{O}_{3}\right)$ and/or silicon carbide $(\mathrm{SiC})$ nanoparticles. This work studied the nanoparticlereinforced epoxy composites using different nano additives, and compared their behavior to the hybrid nanoadditives in order to improve the mechanical behavior of the epoxy composites. Additionally, the effect of weight percentage, wt. \%, of the nanoparticles on the mechanical and tribological properties, is investigated. Finite Element Analysis (FEA) is introduced to simulate the indirect tension test and SPT, to give a complete understanding of the stress distribution in the specimen during loading, as well as its mode of failure. One of the main objectives of using FEA is to predict the material-dependent empirical constant in SPT.

\section{EXPERIMENTAL WORK}

\subsection{Materials}

A composite material contains a commercial resin and a hardener with additive nanoparticles. To achieve complete hardening of the epoxy, a $12 \%$ hardener was used. Before adding the hardener, however, additive nanoparticle types with various percentages were thoroughly mixed in the solution. In the present study, aluminum oxide $\left(\mathrm{Al}_{2} \mathrm{O}_{3}\right)$ nanoparticles and silicon carbide $(\mathrm{SiC})$ were selected as nanoparticle additives. These were purchased from Hongwu International Group, Ltd., of the People's Republic of China. The size and shape of the nanoparticles chosen for use have an average spherical diameter around $50 \mathrm{~nm}$. The physical and mechanical properties of the nanoparticles are listed in Table 1. 
Table 1 Selected physical properties of the nanoparticles used in the study.

\begin{tabular}{ccc}
\hline Material & $\mathrm{Al}_{2} \mathbf{O}_{3}$ & SiC \\
\hline Color & White & Black \\
Density $\left(\mathrm{gm} / \mathrm{cm}^{3}\right)$ & 3.98 & 3.3 \\
Tensile Strength $(\mathrm{MPa})$ & 416 & 588 \\
Fracture Toughness $(\mathrm{MPa} \sqrt{\mathrm{m}})$ & 5 & 4.6 \\
Hardness $(\mathrm{MPa})$ & 22050 & 27468 \\
\hline
\end{tabular}

\subsection{Preparation of Nanoparticles Composite Samples}

The nanoparticles were mixed with the epoxy resin by using a sonicator apparatus (Model POWERSONIC 405 with frequency $=40 \mathrm{KHz}$ ) as shown in Figure 1 . The mixture was placed in the sonicator apparatus at a temperature of $40^{\circ} \mathrm{C}$ for two hours to disperse the nanoparticles in the resin. Subsequently, a $12 \%$ hardener was added to the mixture; this was added with gentle mechanical stirring to ensure uniform mixing and to avoid formation of bubbles. After that, the mixture was poured into a foam mold. The mold geometry and weight percentage of the additives were changed according to the test type, as discussed in the next section.
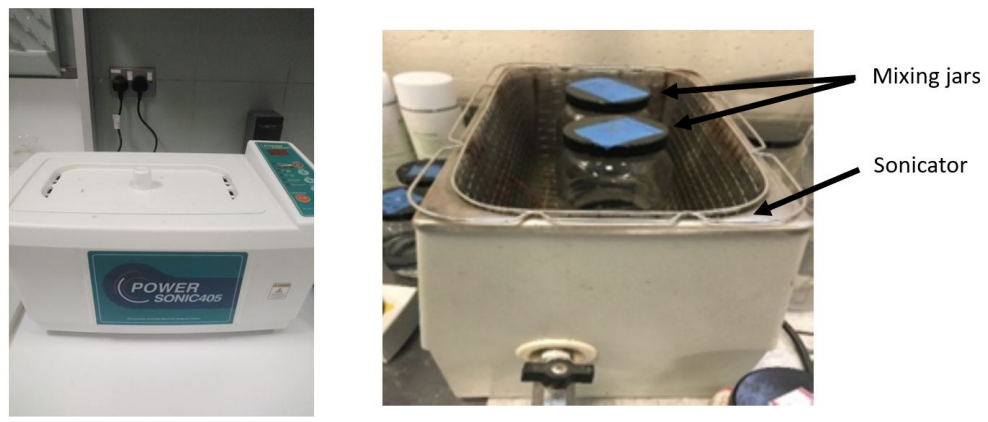

Figure 1 Sonicator apparatus

\subsection{Sample and Tests Characterization}

Five specimens for each test are used to confirm the results. The wear test, indirect tensile test, and SPT are performed at room temperature.

\subsubsection{Wear Test}

The wear resistance tests are divided into two stages. In the first stage, the samples were prepared by adding $1.5 \%$ wt. of $\mathrm{Al}_{2} \mathrm{O}_{3}$, $\mathrm{SiC}$, or hybrid to the epoxy resin in order to determine the additive that can best improve the wear resistance of the epoxy. The samples were labeled in this stage as $S_{1}, S_{2}, S_{3}$, and $S_{4}$, as shown in Table 2.

As shown in the results section, the aluminum oxide $\left(\mathrm{Al}_{2} \mathrm{O}_{3}\right)$ improves the wear resistance of the epoxy resin better than silicon carbide ( $\mathrm{SiC}$ ). Therefore, in the second stage of the wear testing, a different weight content percentage, wt. $\%$, of $\mathrm{Al}_{2} \mathrm{O}_{3}(0.5,1,1.5,2$, and 3$) \%$ are used to determine the optimum wt. \% ratio. The samples were coded in the second stage as $S_{5}, S_{6}, S_{2}, S_{7}$, and $S_{8}$, as shown in Table 2 . Furthermore, one sample was prepared without any additive particles, to serve as a reference. All specimens have been evaluated in the environmental conditions. In the present wear tests, each sample was fixed on a pin and then placed on new sandpaper for each test, at a fixed distance from the disk center.

Table 2 The mixing ratios of various epoxy composites containing

\begin{tabular}{ccc}
\hline Specimen & Alumina, $\mathbf{A l}_{\mathbf{2}} \mathbf{O}_{\mathbf{3}}$, nanoparticles wt\% & Silicon Carbide, SiC, nanoparticles wt\% \\
\hline$S_{1}$ & 0 & 0 \\
$S_{2}$ & 1.5 & 0 \\
$S_{3}$ & 0 & 1.5 \\
$S_{4}$ & 1.5 & 1.5 \\
$S_{5}$ & 0.5 & 0 \\
$S_{6}$ & 1 & 0 \\
$S_{7}$ & 2 & 0 \\
$S_{8}$ & 3 & 0 \\
\hline
\end{tabular}


The wear resistance tests of the resin composites containing various nano-additives and neat resin composites were conducted according to ASTM F732 standards (ASTM, 2017) using a custom-built tribometer (Figure 2). In this test, five cylindrical specimens $(24 \mathrm{~mm}$ in height and $17.6 \mathrm{~mm}$ in diameter) for each material were tested against a bare-wood sandpaper disk with a grit size of 220. Then a typical load of $5 \mathrm{~N}$ was applied to the specimens, after which the disk used as the abrasive counter-face was rotated at a velocity of $20 \mathrm{rpm}$ for five minutes. The wear results show an average of five wear test specimens for each tested material reported with $95 \%$ confidence intervals. The relative velocity of the pin and rotating disc is fixed for all tests, since it is proportional to the disc's rotation speed multiplied by the distance of the pin from the rotation axis, which is fixed on all tests. Finally, the average relative wear amount, weight loss, and wear rate was calculated according to the method reported by (Czichos et al., 1987).
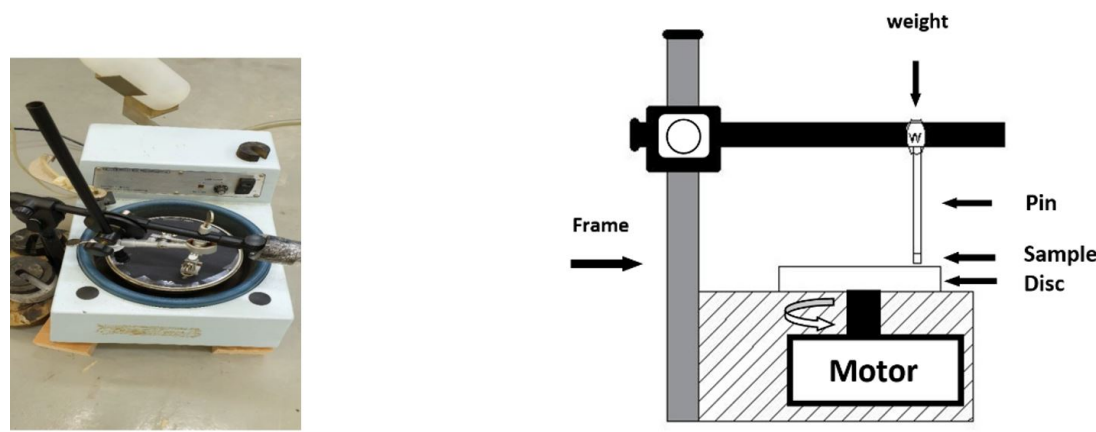

Figure 2 Custom-built tribometer used in this study

\subsubsection{Indirect Tensile Test (Diametral Tensile Test)}

The indirect tensile test is used in many applications (Cesero et al. 2017) to measure the diametral tensile strength, DTS, of nanoparticles composite materials. A cylindrical-shaped specimen with a diameter of $16 \mathrm{~mm}$ and a height of 32 $\mathrm{mm}$, is used as shown in Figure 3. The samples used in the present test have varying wt. \% of $\mathrm{Al}_{2} \mathrm{O}_{3}(0,0.5,1.5$, and 3$) \%$, denoted as $S_{1}, S_{5}, S_{2}$, and $S_{8}$ (Table 2); and are used to study the effects of nanoparticle wt. \% on the DTS. The diametral tensile strength tests were conducted using a 100kN Universal Testing Machine INSTRON-8801 with a crosshead speed of $0.75 \mathrm{~mm} / \mathrm{min}$. The diametral tensile strength ( $\sigma D S)$, DTS, was then computed using the following equation (Anusavice et al., 2012; Canay et al., 1999):

$\sigma_{D S}=\frac{2 F}{\pi d t}$

Where $F$ is represents the fracture load, $d$ is the diameter of the specimen, and $t$ is the thickness of the specimen.

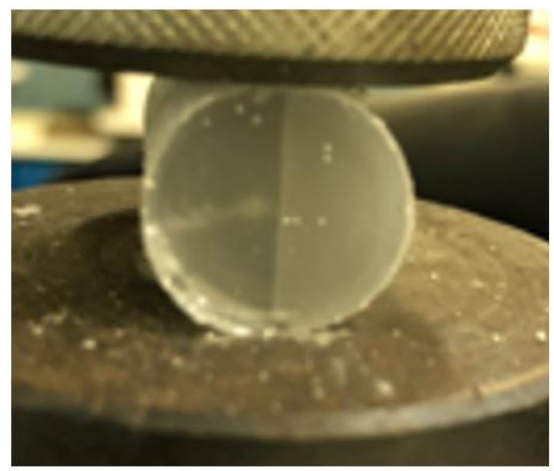

Figure 3 Sample of diametral tensile test

\subsubsection{Small Punch Test (SPT)}

The small punch tests were carried out using an experimental device like the one shown in Figure 4. This device was custom-designed and manufactured in our laboratory, and was mounted on a universal testing machine fitted with a $20 \mathrm{kN}$ load cell. The diameter of the SPT specimen is $20 \mathrm{~mm}$ with a thickness of $2 \mathrm{~mm}$. The SPT in the present work is used to describe the effect of the nanoparticle wt. \% of $\mathrm{Al}_{2} \mathrm{O}_{3}(0,0.5,1.5$, and 3$) \%$ as $S_{1}, S_{5}, S_{2}$, and $S_{8}$ (Table 2 ) on the stiffness of composite specimen. The load-displacement response from initiation until failure is traced for each specimen. 


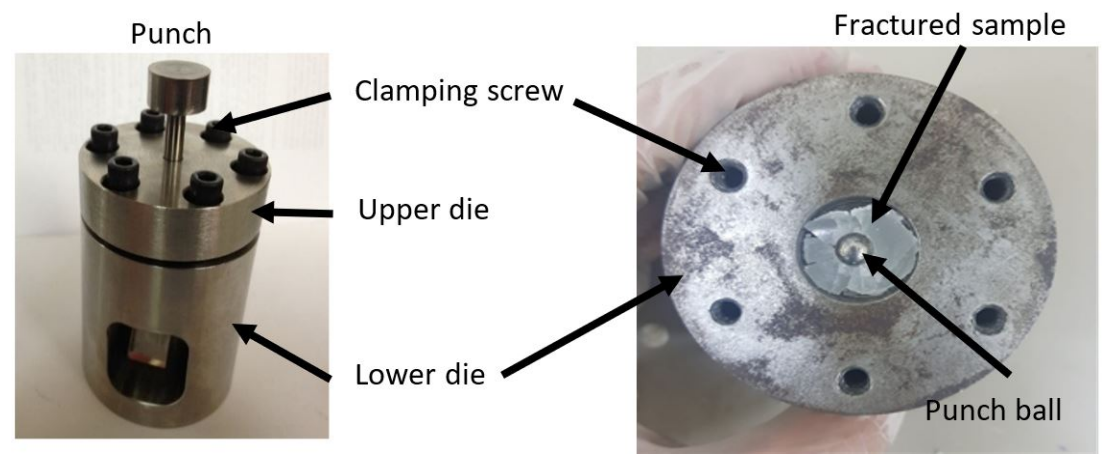

Figure 4 Small punch test setup

\section{Numerical Work}

A 3D finite element code developed by using the ABAQUS program (ABAQUS,2016)is used to simulate an indirect tension test and SPT. The present model is used to describe the stress distribution and the failure shape of the nanocomposite specimen during the tests. The dimensions of the nanocomposite specimens undergoing indirect testing and SPT are taken as the experimental geometry. The extended finite element method (XFEM) is used in the present simulation of the failure of nanocomposite specimens in the indirect tension test and in the small punch test. The XFEM has been used previously in many applications (Mubaraki et al.,2017;Abd-Elhady et al.,2020) to predict the failure shape with high precision. To simplify the calculation of the XFEM model, nanocomposite specimens are simulated using linear elastic properties extracted from the SPT and indirect tensile tests.

Typical finite elements meshing configurations using an indirect tension test and a small punch test are shown in Figure 5. The C3D8R, an eight-node linear brick of the reduced integration element type is used to simulate the present tests and nanocomposite specimens as shown in Figure 5. The load-displacement control is used in the present tests. In the present simulation, the contact between the surfaces of each part is simulated using a penalty friction formulation.

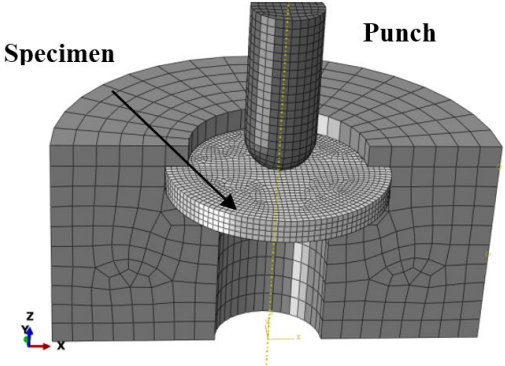

(a)

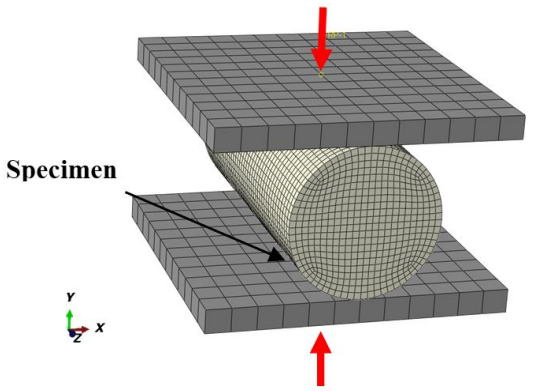

(b)

Figure 5 Finite element model of (a) small punch specimen and (b) indirect tension test

\section{Results and discussion}

\subsection{Wear resistance test results}

The outcomes shown by Figure 6 indicate that nano-additive materials influence the wear behavior of the resin epoxy composites. The wear rate dramatically decreased after introducing the nanoparticles to the resin composite. The nano-additives help distribute the load in the boundary condition wear test, as the additives act like nanoscale ball bearings. When $\mathrm{Al}_{2} \mathrm{O}_{3}$ nanoparticles were added to the composite, the specimen showed better wear resistance, as compared to the addition of $\mathrm{SiC}$ nanoparticles.

In the present two-body abrasive wear test, the samples were in dry contact, and with the increase in abrading distance, some of the worn asperities adhered to the contact area. The results showed that in the cases where SiC nanoparticles were added, the debris removed from the surfaces contact reduces the wear resistance slightly when compared with $\mathrm{Al}_{2} \mathrm{O}_{3}$. Here, the broken $\mathrm{SiC}$ particles can act as a third body abrasive, leading to enhanced roughening of the counter surface and increasing the wear rate. Furthermore, in the samples containing hybrid nano- $\mathrm{Al}_{2} \mathrm{O}_{3}$ and $\mathrm{SiC}$, the average wear amount was slightly higher than that of samples containing only $\mathrm{Al}_{2} \mathrm{O}_{3}$ nanoparticles. Hence, the high hardness for silicon carbide could contribute to reducing wear resistance performance due to the three-body stuck between surface asperities on the wear track; the materials on the wear track cause some damage to the wearing surface. This finding is in 
agreement with Mohan et al. (2010), who stated that with an increase in abrading distances, the wear debris consists of a shear deformed polymer matrix containing broken SiC particles on the counter surface. The particles can either be lost from the contact zone or remain there for a fixed time as a transfer layer. In such cases, their polymer component can provide a barrier for the counter surface asperities and reduce the effective toughness. The particles, however, can act as a third body abrasive leading to enhanced roughening of the counter surface. Hence the wear loss increases with an increase in abrading distances. On the other hand, Vinod et al. (2018) concluded that in abrasive wear tests, the composite samples mainly depend on the grit size of the abrasive paper, abrading distance, applied load, and speed.

On the other hand, this result might be due to the hardness of SiC, which may affect the surface asperity in the contact area. In addition, the interfacial adhesion of aluminum oxide particles with epoxy in the local composite is greater than that of SiC; this fact will contribute to an increase in load-bearing. Ahmedizat et al. (2020) showed that in the case of the sliding wear test, abrasive wear on the sample's surface was produced and resulted in three body wear on the contact area. These results revealed that introducing nano-additives to the composites increased their ability to resist abrasive wear (Ahmedizat et al., 2020). It is suggested that $\mathrm{Al}_{2} \mathrm{O}_{3}$ nanoadditives were influenced the kinetic energy of the resin composites. This in turn led to reinforcing the epoxy by absorbing kinetic energy, which is resulted in reducing the plastic deformation (Vaisakh et al.,2016). It is shown that adding nanoparticles to the epoxy resin can affect the heat generation at the contact surfaces, thus reducing the material loss; this could be the reason that $\mathrm{Al}_{2} \mathrm{O}_{3}$ additives showed better tribological properties.

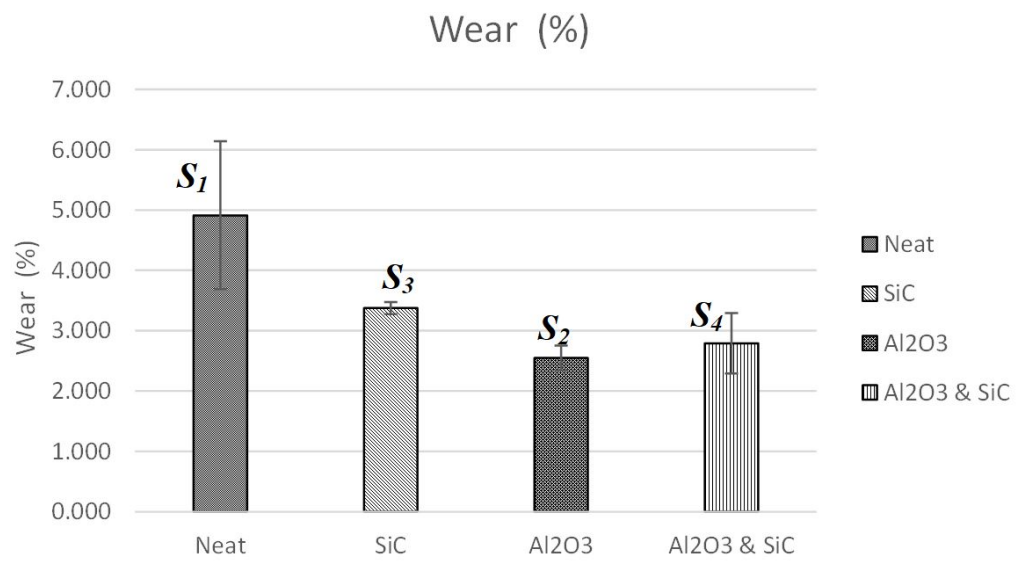

Figure 6 The wear test results with various additive materials

Figure 7 shows the average weight loss, reported with 95\% confidence intervals, according to the various weight percentages of the $\mathrm{Al}_{2} \mathrm{O}_{3}$ additives. The results show that average wear percentages with $\mathrm{Al}_{2} \mathrm{O}_{3}$ nano-additives are similar when the additives are added by $0.5 \mathrm{wt} . \%$ up to $1.5 \mathrm{wt} . \%$. However, the error decreases when the additives increase. On the other hand, wear percentages decreased to an average of $1.7 \%$ for 2 wt.\% and 3 wt. $\% \mathrm{Al}_{2} \mathrm{O}_{3}$ nano-additives. This change in the material's behavior is due to the interfacial bonding strength, because of decreasing interfacing between the particles and epoxy. Of note, mean loads cannot be effectively transferred in a composite. Also, when increasing the quantity of particles of $\mathrm{Al}_{2} \mathrm{O}_{3}$, agglomerations inside the composite are produced and stress concentrators result; these cause a decrease in the bonding strength between the filler and the epoxy material.

\section{Wear of different $\mathrm{Al}_{2} \mathrm{O}_{3}$ nano additives} percentages

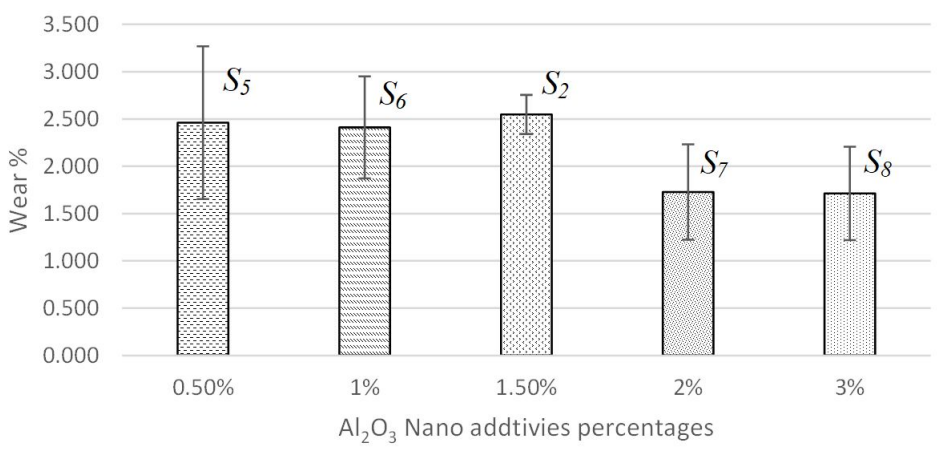

Figure 7 The wear test results with various $\mathrm{Al}_{2} \mathrm{O}_{3}$ additive materials 
Figure 8 shows microscopic images of the worn surfaces of various $\mathrm{Al}_{2} \mathrm{O}_{3}$ samples. It can be seen that the presence of abrasive wear extends over the entire surface of the composites. In Figure 8(a), clear evidence of micropitting and cracks contributes to the weight loss of the neat samples. When compared to the composite surface, after introducing the nanoparticles, the pitting and cracks become less prominent.

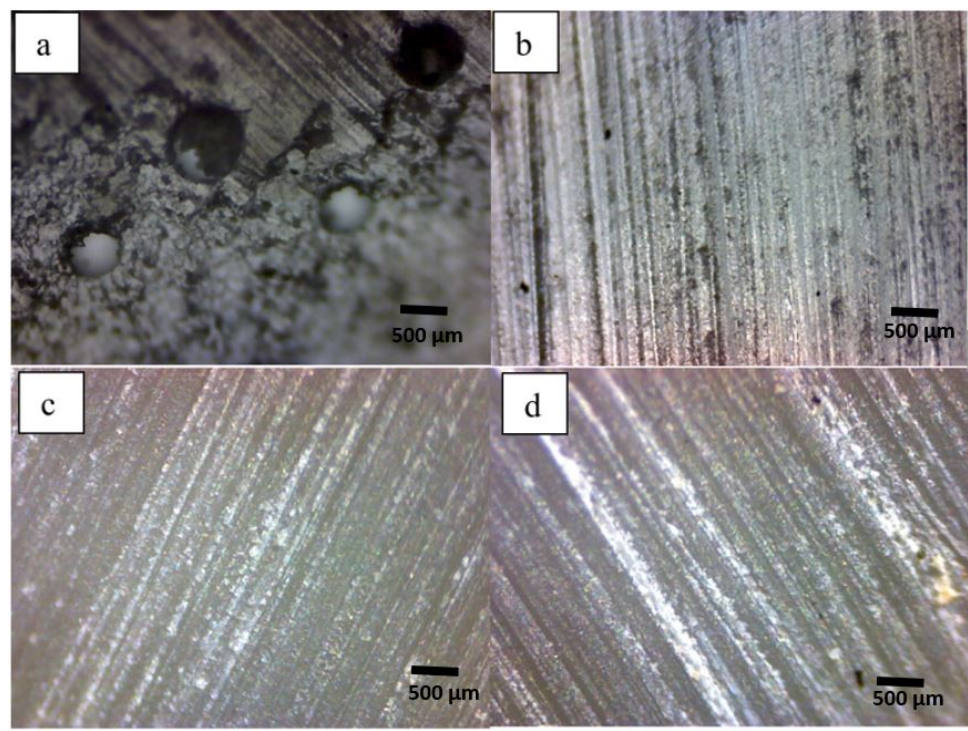

Figure 8 (a) Neat samples (S1), (b) 0.5 wt\% $\mathrm{Al}_{2} \mathrm{O}_{3}(\mathrm{~S} 5)$, (c) 1 wt\% $\mathrm{Al}_{2} \mathrm{O}_{3}$ (S6) and (d) 3 wt\% $\mathrm{Al}_{2} \mathrm{O}_{3}(\mathrm{~S} 8)$.

The addition of $0.5 \mathrm{wt} . \% \mathrm{Al}_{2} \mathrm{O}_{3}$ nanoparticles show that the self-lubrication of aluminum oxide occurs on the epoxy as an adhered layer on the surface. The protective layer improved the wear resistance behavior of the epoxy. However, there are still cracks and micropitting areas on the surface, even when increasing the additive percentage of the surface of the product.. The quantity of cracks and micropitting increased slightly when the nanoparticles percentages increased. There is, however, some variance in the average wear results, which could be due to the nanoparticles' agglomeration; this affects the distribution and density of the adhesive layer on the surface, as shown in Figure 8.

\subsection{Indirect tensile test (diametral tensile test) results}

\subsubsection{Experimental results}

Figure 9 shows the average diametral tensile strength of specimens $S_{1}, S_{5}, S_{2}$, and $S_{8}$. The results show that the composites with no nanoadditives have an average DTS of $81.90 \pm 2$. When introducing $\mathrm{Al}_{2} \mathrm{O}_{3}$ nanoparticles to the epoxy resin by $0.5 \%$, the wt. \% of the DTS was reduced to an average of $51.35 \pm 2$. Moreover, increasing the weight percentage of $\mathrm{Al}_{2} \mathrm{O}_{3}$ nanoparticles in the epoxy resin to $1.5 \%$ and $3 \%$ decreased the average value of the DTS to $45.48 \pm 2$ and $40.79 \pm 2$, respectively. This result indicates that more additives in the composite will result in a lower DTS value. This result is consistent with the results mentioned in (Cesero et al.,2017). The reduction of the tensile strength may be due to the weakening of the adhesion between the epoxy and $\mathrm{Al}_{2} \mathrm{O}_{3}$ nanoparticles. This result is in agreement with the results obtained by Bazrgari et al. (2018), who stated that in the case of the high content ratio of $\mathrm{Al}_{2} \mathrm{O}_{3}$ nanoparticles, the adhesion between the epoxy matrix and $\mathrm{Al}_{2} \mathrm{O}_{3}$ nanofillers became weakened.

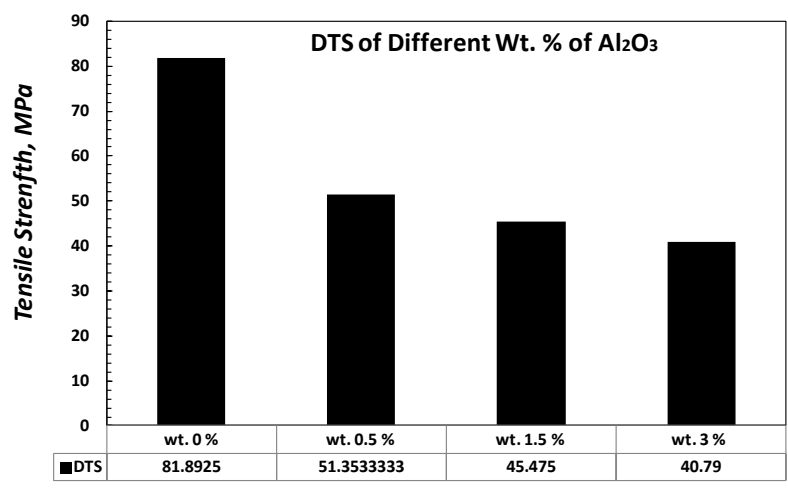

Figure 9 Average Diametral Tensile Strength (DTS) of various $\mathrm{Al}_{2} \mathrm{O}_{3}$ nano additives concentration 
Figure 10 shows the fractured surface of the neat and reinforced epoxy samples. A sample with a high percentage of the reinforcement of $\mathrm{Al}_{2} \mathrm{O}_{3}$ has more fracture debris than other samples. Also, increasing the nano additives percentages raises the possibility of nanoparticle agglomeration when dispersed. It reduces the DTS value because voids result when the additives shift inside the matrix. Naous et al. (2006) found that neat epoxy exhibits relatively smooth fracture morphology. However, the fracture surfaces of the nanocomposites present a much rougher fracture surface with massive plastic deformation both in the crack initiation region and in the crack propagation region. Verma et al. (2020) studied the effect of particle size and morphology of nano- $\mathrm{Al}_{2} \mathrm{O}_{3}$ on tensile and fracture properties of the epoxy alumina composite. They found that the crack deflection and matrix spalling were major factors behind the incremental increase in fracture toughness with spherical $\mathrm{Al}_{2} \mathrm{O}_{3}$ nanofillers. However, crack tilting, crack twisting, crack deflection, and crack bridging were factors behind the incremental increase in fracture toughness, of composites filled with $\mathrm{Al}_{2} \mathrm{O}_{3}$.

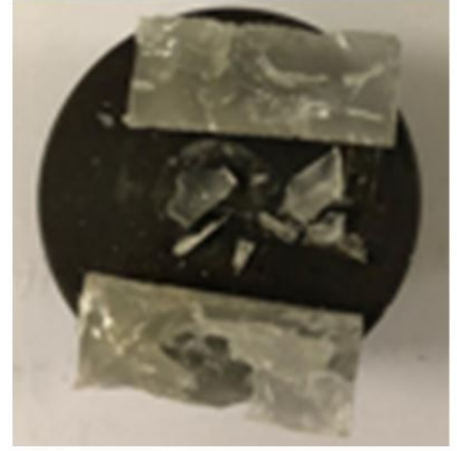

(a)
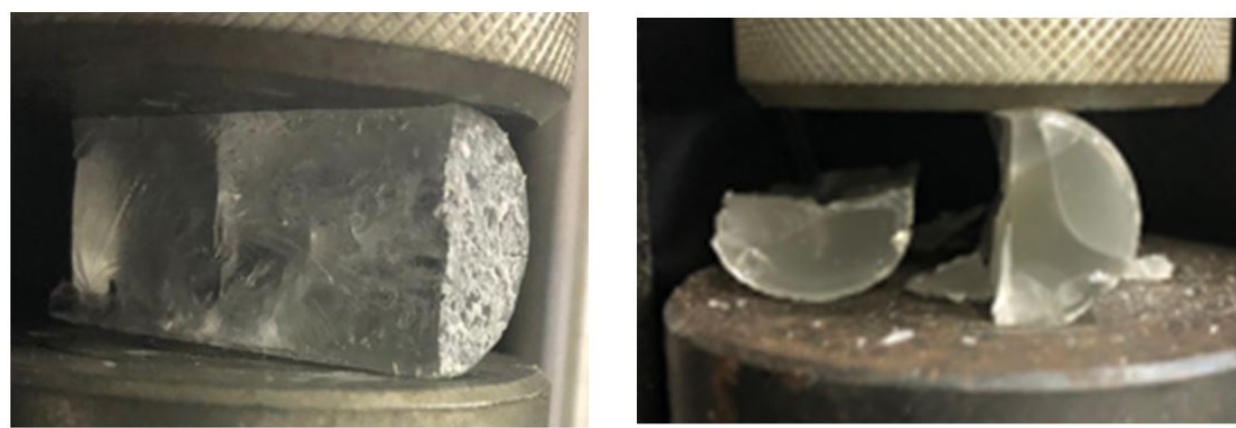

(b)

Figure 10 Fracture surfaces of different composite contents. (a) $1.5 \mathrm{Al}_{2} \mathrm{O}_{3}\left(\mathrm{~S}_{2}\right)$ and (b) neat epoxy $\left(\mathrm{S}_{1}\right)$

\subsubsection{Numerical results}

The numerical analysis is used to generate a deeper understanding of the stress distribution through the indirect specimen during the crack growth. Figure 11 illustrates the fracture shape of the indirect tensile test specimen, and expresses damage both numerically and experimentally. There is agreement between the experimental and the numerical results.

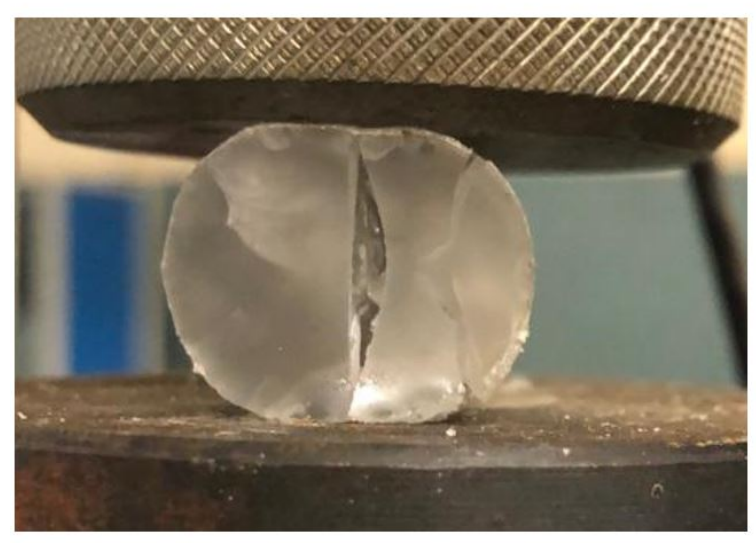

Experimentally

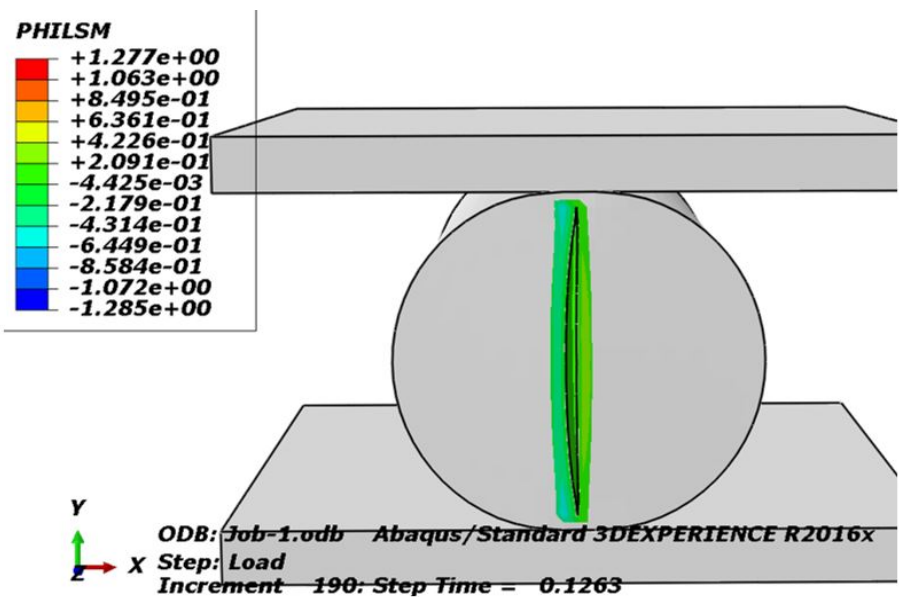

Numerically

Figure $11 \mathrm{~A}$ comparison between the experimental and numerical findings for the fracture specimen shape under the indirect tensile test.

Figure 12 illustrates the distribution of the tensile stress at the vertical diameter during the crack growth. As shown in Figure 12, it can be concluded that the maximum value of tensile stress is located at the center of the specimen; the crack that begins at the center of the specimen then grows parallel to the load and perpendicular to tensile stress. Consequently, the maximum tensile stress is located in the front of the advancing crack tip. 


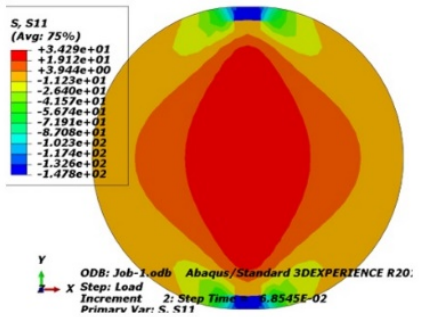

Crack length $=0$

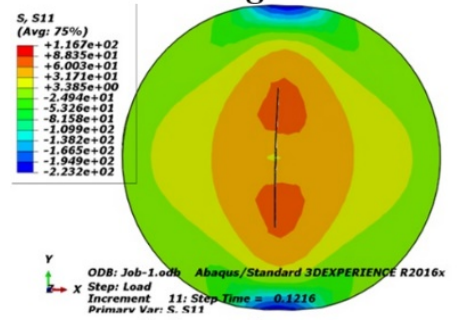

Crack length $=7 \mathrm{~mm}$

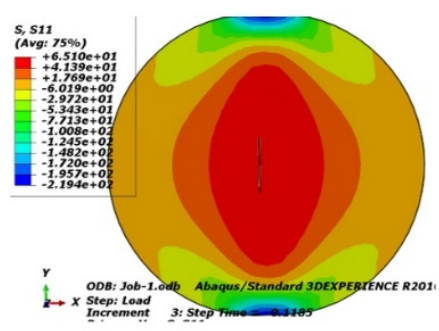

Crack length $=4 \mathrm{~mm}$

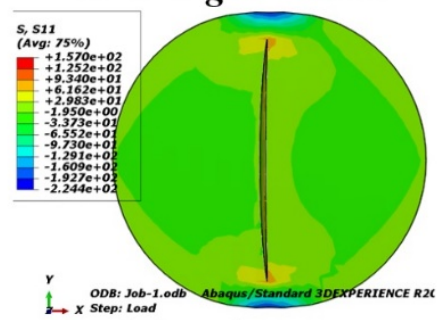

Crack length $=12 \mathrm{~mm}$

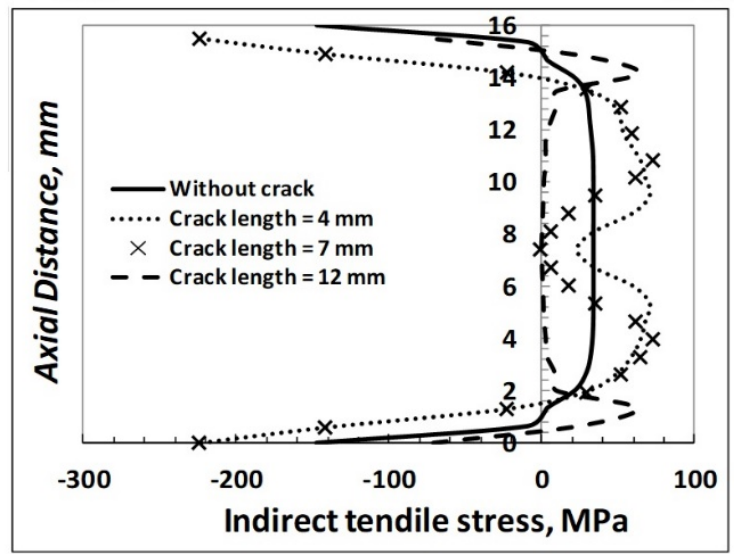

Figure 12 Stress distribution along the cylinder diameter through the development of the crack.

\subsection{Small punch test results}

\subsubsection{Experimental results}

Figures 13(a) and 13(b) show the load versus displacement, as extracted from the experimental results of SPT, with the maximum values respectively for epoxy reinforced with different wt. $\%$ of $\mathrm{Al}_{2} \mathrm{O}_{3}$ nanoparticles $\left(S_{1}, S_{5}, S_{2}\right.$, and $\left.S_{8}\right)$. As shown in Figure 13(a), the behavior of the load-displacement curve of epoxy without nanoparticles is different from that of $\mathrm{Al}_{2} \mathrm{O}_{3}$ nanoparticles. Furthermore, increasing $\mathrm{Al}_{2} \mathrm{O}_{3}$ nanoparticles increases the brittleness of the epoxy so that the force drops (pop-ins) (Vaisakh et al., 2016; ASTM, 2020) caused by crack initiation can be shown in Figure 13(a). Moreover, all shapes of the load-displacement curves of specimens $S_{1}, S_{5}, S_{2}$, and $S_{8}$ are different from the common loaddisplacement curves of metallic ductile materials. The curve is distinguished by five zones (Chica et al.,2017;ASTM, 2020): (elastic - transition between elastic and plastic - plastic hardening - damage initiation - crack growth until failure) until damage takes place.

From Figure 13(b) it is seen that the maximum SPT force decreases with increasing the wt. \% of nanoparticles. The samples without additives show more resistance when compared to other reinforced samples. For the elastic stage of the SPT curve, as shown in Figure 13(a), the reinforced samples have less stiffness compared to the unreinforced samples. Furthermore, the modulus of elasticity, $E$, of the specimen can be estimated by using the value of the slope of the elastic region of SPT load-displacement (Chica et al., 2017), and it follows that the empirical correlations between SPT experimental results and $\mathrm{E}$ can be given as: 
where $\ddot{e}$ is correlation factor computed by using the modulus of elasticity of the epoxy (3.7 GPa). Figure 14 depicts the value of Young's modulus of samples $S_{1}, S_{5}, S_{2}$, and $S_{8}$, which is computed from Equation (2). From Figure 14 it can be seen that the modulus of elasticity decreases by using nanoparticles of $\mathrm{Al}_{2} \mathrm{O}_{3}$.
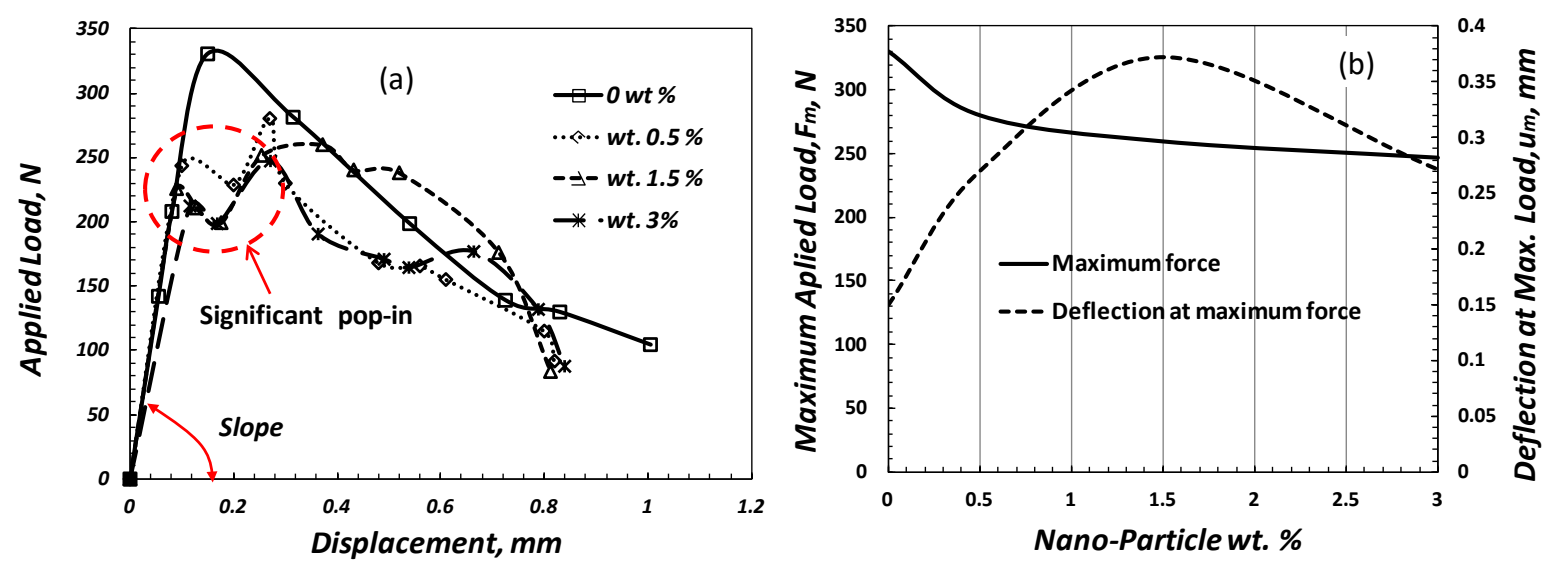

Figure 13 (a) SPT Load-deflection curve; and (b) maximum values of load and deflection extracted from SPT, for nanoparticle composite samples with varying wt. \% of $\mathrm{Al}_{2} \mathrm{O}_{3}$.

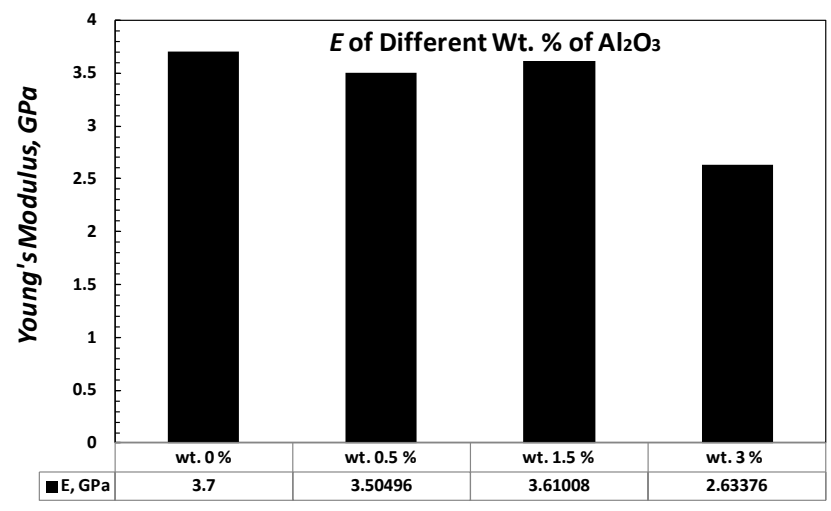

Figure 14 Young's modulus of various $\mathrm{Al}_{2} \mathrm{O}_{3}$ nano additives concentrations

Likewise, the empirical correlations equation between experimental SPT results and ultimate tensile strength can be used for the estimation of the ultimate tensile strength $(u)$ :

$\sigma_{u}=\beta_{U T S} \frac{F_{m}}{t u_{m}}$

where $F_{m}$ is the maximum force during SPT; $u_{m}$ is the specimen deflection corresponding to maximum force $F_{m} ; t$ is the specimen thickness $(2 \mathrm{~mm})$; and $\hat{a}_{U T S}$ is a material-dependent empirical constant. This is accomplished by using the experimental data for the tensile strength values measured from the indirect tensile test, as shown in Figure 9 . The estimated value of $\hat{a}_{\text {UTS }}$ can be obtained as shown in Figure 15. This estimated value increased with increasing the value of $\mathrm{Al}_{2} \mathrm{O}_{3} \%$ up to $1.5 \%$ and then decreased. Figure 16 shows the fracture sample for the unreinforced sample; the fractures are completely brittle, which can be noticed from the fracture behavior.

\subsubsection{Numerical results}

The present section illustrates the simulation results of SPT by using the finite element method to depict the site of crack initiation and distribution of the bending stress through the specimen. Figure 17 shows the numerical elastic bending stress distribution of the SPT specimen through the specimen thickness. The site of crack imitation is located at the bottom of the specimen at its tension side. Furthermore, the crack initiated from the bottom of the specimen and then grew circularly, as shown in Figure 18. 


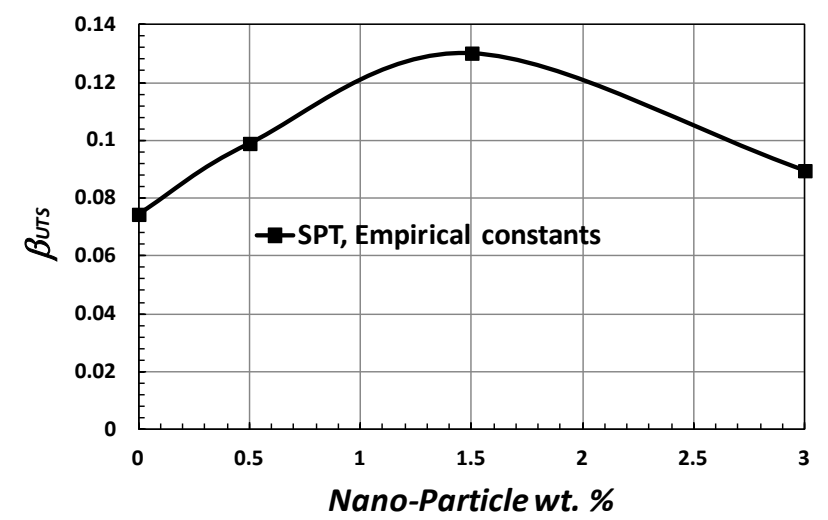

Figure 15 Material-dependent empirical constants, $\hat{a}_{U T S}$, versus wt. $\%$ of $\mathrm{Al}_{2} \mathrm{O}_{3}$ nanoparticle.
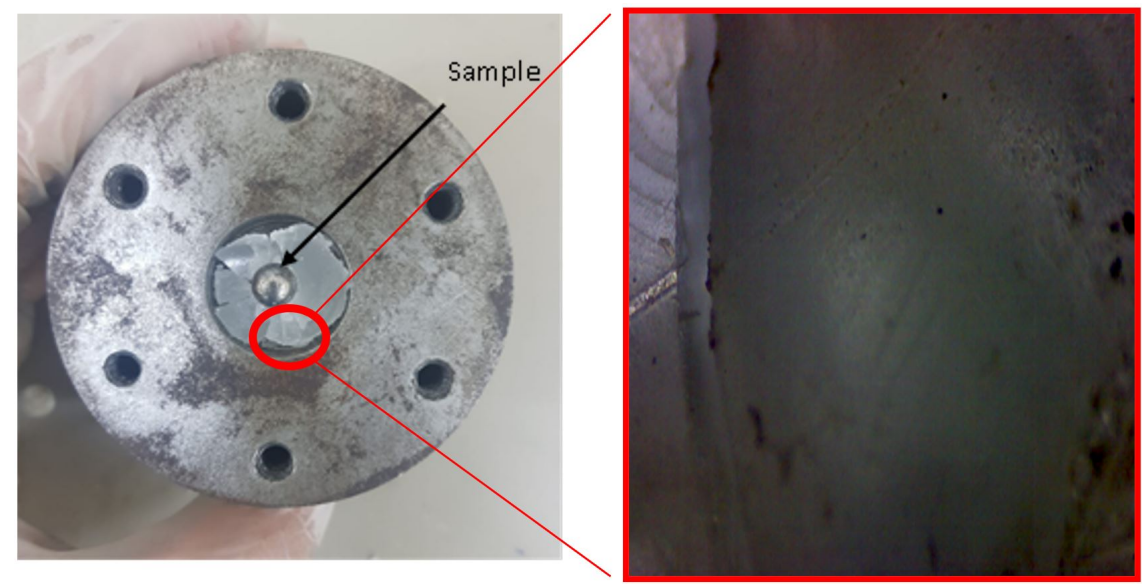

Figure 16. Fractured SPT sample.
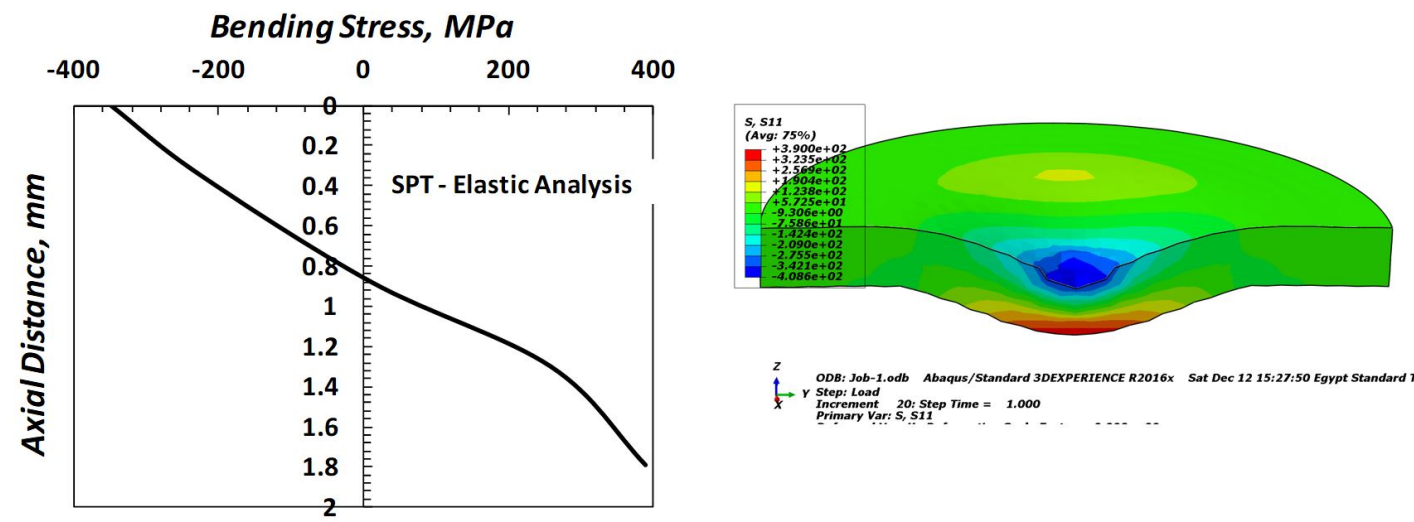

Figure 17 The bending stress distribution of the SPT specimen
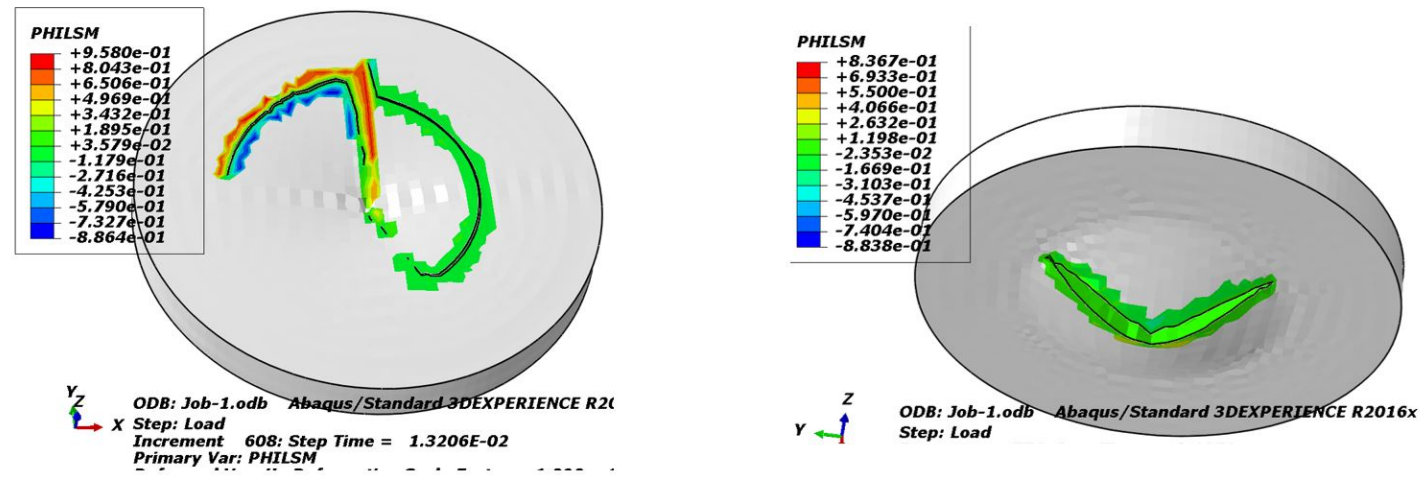

Figure 18 The numerical fracture specimen shape of SPT. 


\section{CONCLUSION}

Based on the results of this study, the following conclusions can be drawn:

- The wear rate dramatically decreased after introducing the nanoparticles to the resin composite.

- The addition of $\mathrm{Al}_{2} \mathrm{O}_{3}$ nanoparticles to the epoxy resin resulted higher resistance to wear than when $\mathrm{SiC}$ or hybrid nanoparticles were added. This means that a synergistic property has not been achieved in improving the wear resistance of epoxy-containing nanoparticles.

- The addition of $2 \% \mathrm{Al}_{2} \mathrm{O}_{3}$ nanoparticles to epoxy resin was found to be the optimum ratio in the present work.

- On the other hand, the tensile strength and modulus of elasticity of epoxy are reduced by adding the $\mathrm{Al}_{2} \mathrm{O}_{3}$ nanoparticles.

- To generalize the SPT, the $\hat{a}_{U T S}$ material-dependent empirical constant can be predicted by equating the tensile strength measured from SPT and the indirect tension test.

- FEA is a good candidate to demystify and interpret experimental results.

\section{Acknowledgments}

This research was supported by the Deanship of Scientific Research (DSR) at Jazan University, KSA. Project: DSR \# Waed-41-29.

Author's Contributions: Conceptualization, WH Alhazmi, Y Jazaa and S Mousa; Methodology, AA Abd-Elhady and WH Alhazmi; Investigation, Y Jazaa and S Mousa; Writing - original draft, WH Alhazmi, Y Jazaa and S Mousa; Writing - review \& editing, HEM Sallam; Funding acquisition, WH Alhazmi; Supervision, AA Abd-Elhady and HEM Sallam.

Editor: Marcílio Alves.

\section{References}

ABAQUS. (2016). ABAQUSanalysis user's guide: Technical Report ABAQUS6.14 Documentation, Simulia Corp.

Abd-Elhady, A.A., Sallam H.E., Alarifi, I.M., Malik, R.A., and El-Bagory, T.M.A.A. (2020). Investigation of fatigue crack propagation in steel pipeline repaired by glass fiber reinforced polymer, Composite Structures, 242: 112189

Agwa, M., Youssef, S.M., Ali-Eldin, S.S., and Megahed, M. (2020). Integrated vacuum assisted resin infusion and resin transfer molding technique for manufacturing of nano-filled glass fiber reinforced epoxy composite, Journal of Industrial. doi:10.1177/1528083720932337

Ahmedizat, S.R., Al-Zubaidi, A.B., Al-Tabbakh, A.A., Achour, A., and Abdul Hamead A. (2020). Comparative study of erosion wear of glass fiber/epoxy composite reinforced with Al2O3 nano and micro particles, Materials Today: Proceedings 20: 420427

Anusavice, K., Shen, C. and Rawls, H. (2012). Philips' science of dental materials, Saunders.

Ash, B.J., Rogers, D.F., Wiegand, C.J., Schadler, L.S., Siegel R.W., Benicewicz, B.C., and Apple, T. (2002). Mechanical properties of Al2O3/polymethylmethacrylate nanocomposites, Polymer Composites 23 (6):1014-1025. https://doi.org/10.1002/pc.10497

ASTM E3205-20. (2020). Standard Test Method for Small Punch Testing of Metallic Materials. ASTM International. West Conshohocken. PA.

ASTM F732-17. (2017). Standard Test Method for Wear Testing of Polymeric Materials Used in Total Joint Prostheses. ASTM International. West Conshohocken. PA.

Baller, J., Thomassey, M., Ziehmer, M., and Sanctuary, R. (2011). The catalytic influence of alumina nanoparticles on epoxy curing, Thermochimica acta 517 (1-2):34-39.https://doi.org/10.1016/j.tca.2011.01.029

Bazrgari, D., Moztarzadeh, F., Sabbagh-Alvani, A.A., Rasoulianboroujeni, M., Tahriri, M., and Tayebi, L. (2018). Mechanical properties and tribological performance of epoxy/Al2O3 nanocomposite. Ceramics International 44: 1220-1224. 
Canay, ù., Hersek, N., Çiftçi, Y., and Akça, K. (1999). Comparision of diametral tensile strength of microwave and oven-dried investment materials, The Journal of prosthetic dentistry 82 (3):286-290.DOI: 10.1016/s0022-3913(99)70082-x

Cesero, L.D., D., Oliveira, E.M.N.D., Junior, L.H.B., Papaléo, R.M., and Mota, E.G. (2017). The addition of silica nanoparticles on the mechanical properties of dental stone, The Journal of prosthetic dentistry 118 (4):535-539.DOI:

10.1016/j.prosdent.2017.01.001

Chica, J.C., Díez. P.M.B., and Calzada, M.P.(2017). Improved correlation for elastic modulus prediction of metallic materials in the Small Punch Test, International Journal of Mechanical Sciences 134:112-

122.https://doi.org/10.1016/j.ijmecsci.2017.10.006

Czichos, H., Becker, S., and Lexow, J. (1987). Multilaboratorytribotesting: results from the Versailles advanced materials and standards programme on wear test methods, Wear 114 (1):109-130.https://doi.org/10.1016/0043-1648(87)90020-2

Dass, K., Chauhan, S.R. and Gaur, B. (2017). Study on the effects of nanoparticulates of SiC, Al2O3, and ZnO on the mechanical and tribological performance ofepoxy-based nanocomposites, Particulate Science and Technology, 35(5):589-

606.https://doi.org/10.1080/02726351.2016.1184730

Gong, X., Liu, Y., Wang, Y., Xie, Z., Dong, Q., Dong, M., Liu, H., Shao, Q., Lu, N., Murugadoss, V., Ding, T. and Guo, Z. (2019). Amino graphene oxide/dopamine modified aramid fibers: Preparation, epoxy nanocomposites and property analysis, Polymer 168:131-137.https://doi.org/10.1016/j.polymer.2019.02.021

Gu, H., Zhang, H., Ma, C., Xu, X., Wang, Y., Wang, Z., Wei, R., Liu, H., Liu, C., Shao, Q., Mai, X. and Guo, Z. (2019). Trace electrosprayednanopolystyrene facilitated dispersion of multiwalled carbon nanotubes: simultaneously strengthening and toughening epoxy, Carbon 142:131-140.

He, Y., Chen, Q., Liu, H., Zhang, L., Wu, D., Lu, C., Yang, W.O., Jiang, D., Wu, M., Zhang, J., Li, Y., Fan, J., Liu, C. and Guo, Z. (2019). Friction and wear of MoO3/graphene oxide modified glass fiber reinforced epoxy nanocomposites, Macromolecular Materials and Engineering 304 (8):1900166.https://doi.org/10.1002/mame.201900166

Jiang, T., Kuila, T., Kim, N.H., and Lee, J.H. (2014). Effects of surface-modified silica nanoparticles attached graphene oxide using isocyanate-terminated flexible polymer chains on the mechanical properties of epoxy composites, Journal of Materials Chemistry A 2 (27):10557-10567.https://doi.org/10.1039/C4TA00584H

Kurahatti, R.V., Surendranathan, A.O., Kumar, A.V.R., Auradi, V., Wadageri, C.S., and Kori, S.A. (2014). Mechanical and Tribological Behaviour of Epoxy Reinforced with Nano Al2O3 Particles, Applied Mechanics and Materials 592-594: 13201324https://doi.org/10.4028/www.scientific.net/AMM.592-594.1320

Luo, Y., Rong, M.Z. and Zhang, M.Q. (2007). Tribological behavior of epoxy composites containing reactive SiC nanoparticles, J. Appl. Polym. Sci. 104: 2608-2619.https://doi.org/10.1002/app.24414

Ma, L., Li, N., Wu, G., Song, G., Li, X., Han, P., Wang, G., and Huang, Y. (2018). Interfacial enhancement of carbon fiber composites by growing TiO2 nanowires onto amine-based functionalized carbon fiber surface in supercritical water, Applied Surface Science 433:560-567.https://doi.org/10.1016/j.apsusc.2017.10.036

Ma, L., Zhu, Y, Wang, M., Yang, X., Song, G., and Huang, Y. (2019). Enhancing interfacial strength of epoxy resin composites via evolving hyperbranched amino-terminated POSS on carbon fiber surface, Composites Science and Technology 170:148-156.

Megahed, A.A., Agwa, M.A., and Megahed, M. (2018). Improvement of hardness and wear resistance of glass fiber-reinforced epoxy composites by the incorporation of silica/carbon hybrid nanofillers, Polymer-Plastics Technology and Engineering 57 (4):251-259.DOI: 10.1080/03602559.2017.1320724

Megahed, M., Megahed, A., and Agwa, M. (2019). The influence of incorporation of silica and carbon nanoparticles on the mechanical properties of hybrid glass fiber reinforced epoxy, Journal of Industrial Textiles 49 (2):181199.doi:10.1177/1528083718775978

Megahed, M., Tobbala, D.E., and Abd El-bakym M.A. (2021). The effect of incorporation of hybrid silica and cobalt ferrite nanofillers on the mechanical characteristics of glass fiber-reinforced polymeric composites, Polymer Composites 42 (1):271284.https://doi.org/10.1002/pc.25823

Mohan, N., Natarajan, S., KumareshBabu, S.P., Siddaramaiah, (2010). Investigation on Two-Body Abrasive Wear Behavior of Silicon Carbide Filled Glass Fabric-Epoxy Composites. Journal of Minerals \& Materials Characterization \& Engineering, 9 (3): 231-246. 
Moreno, M. F.(2016). Application of small punch testing on the mechanical and microstructural characterizations of P91 steel at room temperature. International Journal of Pressure Vessels and Piping, 142, 1-9.

Mubaraki, M.A., Abd-Elhady, A.A., Osman, S.A., and Sallam, H.E.M. (2017). Mixed mode fracture behavior of concrete pavement containing RAP-3D finite element analysis, Procedia Structural Integrity 5:19-

26.https://doi.org/10.1016/j.prostr.2017.07.054

Naous, W., Yu, X Zhang,Q., Naito,K., and Kagawa, Y. (2006). Morphology, Tensile Properties, and Fracture Toughness of Epoxy $/ \mathrm{Al}_{2} \mathrm{O}_{3}$ Nanocomposites. Journal of Polymer Science: Part B: Polymer Physics, Vol. 44, 1466-1473.

Rong, M. Z., Zhang, M. Q., Liu, Y., Yang, G. C., \& Zeng, H. M. (2001). The effect of fiber treatment on the mechanical properties of unidirectional sisal-reinforced epoxy composites. Composites Science and technology, 61(10), 1437-1447.

Schwartz, C.J. and Bahadur, S. (2000). Studies on the tribological behavior and transfer film-counterface bond strength for polyphenylene sulfide filled with nanoscale alumina particles. Wear 237 (2):261-273.https://doi.org/10.1016/S00431648(99)00345-2

Suzuki, N., Kiba, S., and Yamauchi, Y. (2011a). Bimodal filler system consisting of mesoporous silica particles and silica nanoparticles toward efficient suppression of thermal expansion in silica/epoxy composites, Journal of Materials Chemistry 21 (38):14941-14947.https://doi.org/10.1039/C1JM12405F

Suzuki, N., Kibab, S. and Yamauchi, Y. (2011b). Fabrication of mesoporous silica/polymer composites through solvent evaporation process and investigation of their excellent low thermal expansion property, Physical Chemistry Chemical Physics 13 (11):4957-4962.https://doi.org/10.1039/C0CP02071K

Vaisakh, S.S., Mohammed, A.A.P., Hassanzadeh, M., Tortorici, J.F., Metz, R., and Ananthakumar, S. (2016). Effect of nanomodified SiO2/Al2O3 mixed-matrix micro-composite fillers on thermal, mechanical, and tribological properties of epoxy polymers, Polymers for Advanced Technologies 27 (7):905-914. https://doi.org/10.1002/pat.3747

Verma, v., Sayyed, A.H.M., Sharma, C., and Shukla, D.K. (2020). Tensile and fracture properties of epoxy alumina composite: roleof particle size and morphology. Journal of Polymer Research 27, 388. https://doi.org/10.1007/s10965-020-02359-z.

Vinod,Kumar, A., Suresh, B., Kumar, M.V.K, and Ramesh, S. (2018).Study on two body abrasive wear behaviour of carboxylgraphene reinforced epoxy nano-composites.IOP Conf.Ser.: Mater. Sci. Eng. 376, 012058

$\mathrm{Xu}$, Y., and Van Hoa, S. (2008). Mechanical properties of carbon fiber reinforced epoxy/clay nanocomposites. Composites Science and Technology, 68(3-4), 854-861.

Youssef, S.M., Agwa, M.A., Ali-Eldin, S.S., and Megahed, M. (2020). Hardness, wear behavior and processing time of diluent and non-diluent nanocomposite laminates manufactured by vacuum infusion technique, Journal of Industrial https://doi.org/10.1177/1528083720970165

Zhang, J., Liang, Y., Wang, X., Zhou, H., Li, S., Zhang, J., Feng, Y., Lu, N., Wang, Q., and Guo Z. (2018a). Strengthened epoxy resin with hyperbranched polyamine-ester anchored graphene oxide via novel phase transfer approach, Advanced Composites and Hybrid Materials 1 (2):300-309.DOI 10.1007/s42114-017-0007-0

Zhang, Y., Zhao, M., Zhang, J., Shao, Q., Li, J., Li, H., Lin, B., Yu, M., Chen, S., and Guo, Z. (2018b). Excellent corrosion protection performance of epoxy composite coatings filled with silane functionalized silicon nitride. Journal of Polymer Research 25 (5):113.https://doi.org/10.1007/s10965-018-1518-2

Zhang, Z., Zhang, J., Li, S., Liu, J., Dong, M., Li, Y., Lu, N., Lei, S., Tang, J., Fan, J. and Guo, Z. (2019). Effect of graphene liquid crystal on dielectric properties of polydimethylsiloxane nanocomposites. Composites Part B: Engineering 176:107338.https://doi.org/10.1016/j.compositesb.2019.107338 